\title{
Analysis of Visual Sensibility Evaluation of Naturally Colored Organic Cotton: Identification of Reliability and Proper Scouring Method
}

\author{
Jangwoon Park ${ }^{1}$, Yoon Chang ${ }^{1}$, Wongi Hong ${ }^{1}$, Myungeun Lee ${ }^{2}$, Ahreum Han ${ }^{2}$, \\ Youngjoo Chae', Gilsoo $\mathrm{Cho}^{2}$, Heecheon You ${ }^{1}$ \\ ${ }^{1}$ Division of Mechanical and Industrial Engineering, \\ Pohang University of Science and Technology, Pohang, Kyungbuk, 790-784 \\ ${ }^{2}$ Department of Clothing and Textiles, Yonsei University, Seoul, 120-749
}

\begin{abstract}
Objective: The present study was intended to identify (1) the intra- and inter-rater reliabilities of a visual sensibility evaluation protocol and (2) the effects of $\mathrm{NaCOC}$ color and scouring method on the visual sensibility of NaCOC. Thirty female participants(20s \& 30s) were participated in the visual sensibility evaluation of NaCOC. Background: Interests in naturally colored organic cotton( $\mathrm{NaCOC}$ ) increase rapidly in parallel with the social trend of eco-friendly living and wellbeing. Method: Three color sets (ivory, green, and coyote-brown) of NaCOC specimens including one untreated and four treated specimens $\left(\mathrm{Na}_{2} \mathrm{CO}_{3} ; \mathrm{NaOH}\right.$; enzyme; boiling water) were examined in the study. The visual sensibility evaluation was conducted by the test-retest method using nine pairs of bipolar visual sensibility adjectives(bright-dark; clear-murky; heavy-light; vivid-subdued; warm-cool; fresh-stale; strong-weak; showy-plain; and luxurious-cheap). Results: As a result of reliability of a visual sensibility evaluation protocol, inter-rater variability(average $\mathrm{SD}=1.06$ ) of visual sensibility evaluation was more than 1.4 times the intra-rater variability(average $\mathrm{SD}=0.74$ ). However, both the sensibility evaluation reliabilities did not show any systematic pattern of changes. Lastly, ANOVA and post-hoc analysis showed that preferred scouring methods for a visual sensibility adjective pair significantly vary depending on NaCOC color. Application: Both the reliability of visual sensibility evaluation protocol and the analysis of proper scoring method of NaCOC in the study would be useful information to design the affective textile.
\end{abstract}

Keywords: Naturally colored organic cotton, Visual sensibility, Reliability, Scouring method

\section{Introduction}

친환경 소재와 웰빙 (well-being)에 대한 소비자의 관심 이 높아짐에 따라 의복 설계 분야에서는 천연 착색 유기농 섬유 (naturally colored organic cotton; $\mathrm{NaCOC}$ ) 의 활용이 증대되고 있다. $\mathrm{NaCOC}$ 는 인위적인 염색 처리 없이 고유의 색을 지니며 주로 녹색(green) 또는 갈색(brown)을 띄는
것으로 알려져 있다(Dickerson et al., 1999). 또한 $\mathrm{NaCOC}$ 는 화학 염료를 사용하지 않기 때문에 의복에 사용될 경우 아토피와 같은 피부 질환을 예방하는데 효과적인 것으로 알 려져 있으며(서명희, 2008), 친환경적 특성으로 인해 향후 의복 산업에 유용하게 활용될 것으로 기대되고 있다(Hua et al., 2007).

섬유 상태의 $\mathrm{NaCOC}$ 를 직물로 제직하기 위해서는 정련 처리 과정을 거치게 된다. 정련 처리(scouring process)란

Corresponding Author: Heecheon You. Division of Mechanical and Industrial Engineering, POSTECH, Pohang, Kyungbuk, 790-784.

Phone: 054-279-2210, E-mail: hcyou@postech.ac.kr

Copyright@2011 by Ergonomics Society of Korea(pISSN:1229-1684 eISSN:2093-8462). All right reserved. 
섬유를 직물로 직조하기에 앞서 섬유에 포함된 미세 먼지를 제거하고 섬유의 흡습성을 향상시키기 위해 수행되는 화학 적 또는 자연적 처리 과정을 의미한다(Lewin \& Pearce, 1985). 이러한 정련 처리는 섬유가 지닌 본래의 색상에 변 화를 유발할 수 있으며 (Kang \& Epps, 2008; Tzanov et al., 2001), 정련 처리로 인한 섬유 색상의 변화는 의복을 구매 하는 소비자들의 시감성에 영향을 미칠 수 있다.

한편 의복 색상에 대한 소비자들의 시감성이 중요해짐에 따라, 섬유와 직물의 색상에 대한 인간의 시감성을 이해하려 는 연구들이 진행되고 있다. Yick et al. (1995)은 직물 관련 산업에 종사하고 있는 평가자들을 대상으로 서로 다른 물리 적 특성을 지닌 여러 직물의 태(handle)에 대해 주관적 감 성 평가를 수행하였는데, 각 평가자들은 직물의 색상, 도안 및 무늬에 대해 상이한 감성 평가 기준이 있음을 보고하였다. Ou et al. (2004)은 단일 색상들에 대한 선호 정도를 10 개 의 감성 형용사 쌍으로 평가하였는데, 실험 참여자의 문화적 배경 (영국, 중국)에 따라 "긴장된(tense)-편안한(relaxed)", "선호(like)-비선호(dislike)" 감성에서 유의한 차이를 보이 는 것을 파악하였다. 예를 들어, 영국인은 동적 색상 (active color)에서 긴장된 감성을 보인 반면, 중국인은 딱딱하고 (hard), 무겁고(heavy), 남성스럽고(masculine), 지저분한 (dirty) 색상에 대해 긴장된 감성을 느끼는 것으로 나타났다.

시감성 측면에서 선호되는 직물을 제직하기 위해 정련 방 법에 따른 $\mathrm{NaCOC}$ 의 색상에 대한 시감성을 평가하고 선호 되는 정련 방법을 찾는 연구가 필요하다. 이에 따라 본 연구 는 다양한 방법으로 정련 처리된 $\mathrm{NaCOC}$ 에 대한 시감성 평 가 실험을 통해 평가 protocol에 대한 신뢰성을 분석하고 시감성 측면에서의 선호되는 정련 방법을 파악하였다. 본 연 구에서 시감성은 20 30대 여성 평가자 30명을 대상으로 3 가지 색상 (ivory, green, coyote-brown color)에 대해 4 가지 정련 방법 $\left(\mathrm{Na}_{2} \mathrm{CO}_{3}, \mathrm{NaOH}\right.$, enzyme, 끓는 물)이 적 용된 총 15 종의 섬유(정련 미처리 포함)를 9 쌍의 시감성 형 용사(예: 밝은-어두운, 맑은-탁한)로 평가되었다.

\section{Materials and Methods}

\subsection{Visual sensibility evaluation protocol}

본 연구의 시감성 평가 실험은 20 30대 여성 30명(평균 연령: 25.8세; SD: 3.3; 범위: 21 34세)이 참여하였다. 실험 에 참여한 모든 참여자들은 정상적인 시력을 지니고 있으며 색맹은 없는 것으로 파악되었다. 시감성 평가 형용사는 기존 연구(이경자와 남수진, 1999; 우승정과 조길수, 2003)를 바 탕으로 9쌍(밝은-어두운; 맑은-탁한; 무거운-가벼운; 선명
한-은은한; 따뜻한-차가운; 산뜻한-칙칙한; 강한-약한; 화 려한-수수한; 고급스러운-값싸 보이는)이 선택되었다. 선 택된 형용사 쌍은 $\mathrm{NaCOC}$ 색상에 대한 선호 중립적인 감 성 (예: 화려한-수수한) 과 더불어 긍정적-부정적 감성 (예: 고급스러운-값싸 보이는) 도 평가할 수 있도록 구성되었다. 평가 척도는 각 형용사 쌍에 대해 7점 척도(예: 매우 탁한: -3점, 중간: 0점, 매우 맑은: 3점)로 설정되었으며, 본 실 험에 사용된 시료는 표 1 과 같이 3 가지 색상(ivory, green, coyote-brown)의 섬유에 대해 Kang and Epps(2008)의 정련 방법을 참조하여 정련 미처리된 시료와 화학적 정련 방 법 $\left(\mathrm{Na}_{2} \mathrm{CO}_{3}, \mathrm{NaOH}\right)$ 및 자연적 정련 방법 (enzyme, 끓는 물)으로 처리된 시료 15 종이 각각 준비되었다.

시감성 평가 실험은 4 단계 절차(실험 소개, 시감성 평가 실험, 휴식, 시감성 반복 평가 실험)로 진행되었다. 실험 소 개 단계에서는 실험 목적과 방법을 실험 참여자에게 설명한 후 실험 참여 동의서를 받았다. 시감성 평가 실험 단계에서 는 실험 참여자가 총 15 종의 $\mathrm{NaCOC}$ 색상에 대한 시감성을 평가하였다. 평가 절차는 먼저 3가지 색상(ivory, green, coyote-brown) 중 하나의 특정 색상(예: ivory)에 대해 정 련 처리되지 않은 기준 시료를 평가한 후, 같은 색상에서 나 머지 4 가지 정련 방법 $\left(\mathrm{Na}_{2} \mathrm{CO}_{3}, \mathrm{NaOH}\right.$, enzyme, 끓는 물 $)$ 으로 처리된 시료들의 시감성을 기준 시료 대비 비교 평가 하는 순서로 진행되었다. 그리고 남은 2가지 색상(예: green, coyote-brown)에 대해서도 기준 시료 대비 정련된 시료들 의 시감성을 무작위 순으로 비교 평가하였다(총 30분 소요). 시감성 평가 실험이 종료된 후에는 실험 참여자에게 5 분의 휴식을 취할 수 있도록 하였다. 마지막으로 반복 평가 실험 단계에서는 휴식을 마친 실험 참여자가 앞서 수행된 평가와 동일한 절차로 시감성을 재평가하였다. 한편, 실험실 내의 조도는 실험에 영향을 주지 않는 범위 내에서 400lux (일반 사무실 권장 조도 수준)로 통제되었다.

\subsection{Visual sensibility analysis protocol}

본 연구는 시감성 평가 protocol의 신뢰성을 파악하기 위 해 평가 및 재평가에 따른 변동(intra-rater reliability) 과 평가자들 간 변동(inter-rater reliability)을 각각 분석하였 다. Intra-rater reliability는 각 평가자들의 평가 및 재평가 결과의 표준편차에 대한 평균값으로 분석되었으며 interrater reliability는 각 평가자들의 평가 및 재평가 결과의 평균값들에 대한 표준편차로 계산되었다. Intra- \& Interrater reliability는 ANOVA와 post-hoc analysis 방법으로 분석되었으며, 3 차 이상의 교호작용은 해석의 난이성 때문에 분석하지 않았다. $\mathrm{NaCOC}$ 의 적정 정련 방법은 각 시감성 평 가 형용사에 대해 섬유의 색상 별로 파악되었다. 
Table 1. Fifteen specimens of $\mathrm{NaCOC}$ for visual sensibility evaluation

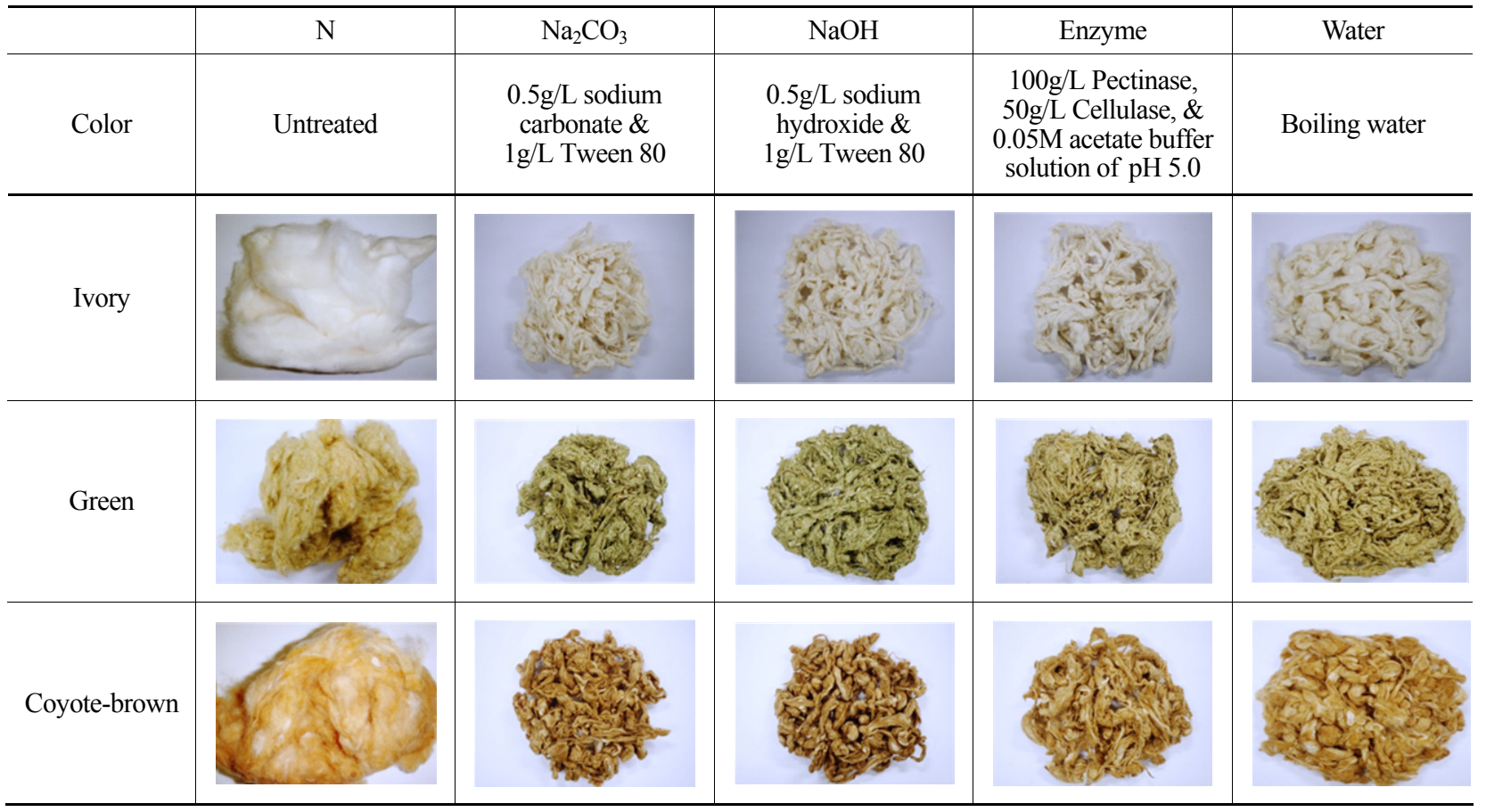

\section{Results}

\subsection{Reliability of visual sensibility evaluation protocol}

$\mathrm{NaCOC}$ 시감성에 대한 intra-rater reliability는 평균 0.74 (범위 $=0.54 \sim 0.89$ )로 나타났으며 체계적인 변화 경 향은 없는 것으로 나타났다. Three-factor within ANOVA 분석 결과(표 2 참조), 섬유의 색상 $(\mathrm{C})$ 과 시감성 형용사 $(\mathrm{SA})$, 색상과 정련 방법의 교호작용 $(\mathrm{C} \times \mathrm{M})$, 색상과 시감 성 형용사의 교호작용 $(\mathrm{C} \times \mathrm{SA})$ 에서 유의한 차이가 있는 것으로 나타났다. 그러나 그림 1 에 나타낸 것과 같이 섬유 의 색상과 정련 방법에 따른 intra-rater reliability는 변 화 경향이 불규칙적인 것으로 나타났으며 변화의 폭(최대값 -최소값 $=0.35$ )도 미비한 것으로 나타났다.

$\mathrm{NaCOC}$ 시감성에 대한 inter-rater reliability는 평균 1.05 (범위 $=0.96 \sim 1.16$ ) 로 나타났으며 intra-rater reliability 분석 결과와 유사하게 $\mathrm{NaCOC}$ 색상과 정련 방법에 의한 변화 경향성은 없는 것으로 분석되었다. Inter-rater reliability는 표 3에 나타낸 것과 같이 시감성 형용사(SA), 색상과 정련 방법의 교호작용 $(\mathrm{C} \times \mathrm{SA})$, 색상과 형용사의 교호작용 $(\mathrm{C} \times \mathrm{SA})$ 에서 유의한 차이가 있는 것으로 나타났 다. 그러나 $\mathrm{NaCOC}$ 색상 별 4가지 정련 방법에 따른 interrater reliability는 그림 2와 같이 특별한 경향성이 없고
Table 2. Intra-rater reliability ANOVA

\begin{tabular}{l|rrrrr}
\hline \multicolumn{1}{c|}{ Source } & \multicolumn{1}{c}{$\boldsymbol{d} \boldsymbol{f}$} & \multicolumn{1}{c}{ SS } & MS & $\boldsymbol{F}$ & $\boldsymbol{p}$ \\
\hline NaCOC color(C) & 2 & 2.64 & 1.32 & $3.18^{*}$ & .042 \\
$\mathrm{~S} \times \mathrm{C}$ & 58 & 90.22 & 1.56 & & \\
Scouring method(M) & 4 & 3.90 & 0.98 & 2.35 & .052 \\
$\mathrm{~S} \times \mathrm{M}$ & 116 & 96.93 & 0.84 & & \\
Sensibility adjective(SA) & 8 & 11.18 & 1.40 & $3.37^{* *}$ & $<.001$ \\
$\mathrm{~S} \times \mathrm{SA}$ & 232 & 111.99 & 0.48 & & \\
$\mathrm{C} \times \mathrm{M}$ & 8 & 21.98 & 2.75 & $6.62^{* *}$ & $<.001$ \\
$\mathrm{~S} \times \mathrm{C} \times \mathrm{M}$ & 232 & 285.44 & 1.23 & & \\
$\mathrm{C} \times \mathrm{SA}$ & 16 & 17.24 & 1.08 & $2.60^{* *}$ & $<.001$ \\
$\mathrm{~S} \times \mathrm{C} \times \mathrm{SA}$ & 464 & 211.01 & 0.45 & & \\
$\mathrm{M} \times \mathrm{SA}$ & 32 & 15.99 & 0.50 & 1.20 & .200 \\
$\mathrm{~S} \times \mathrm{M} \times \mathrm{SA}$ & 928 & 402.93 & 0.43 & & \\
Subject(S) & 29 & 183.70 & 6.33 & & \\
Error & 1918 & 795.80 & & & \\
\hline Total & 4047 & 2251.82 & & & \\
\hline
\end{tabular}

(Note) Interactions of order higher than three were assumed negligible; ${ }^{*} p<.05 ;{ }^{* *} p<.01$.

random한 것으로 나타났다. 한편 inter-rater reliability (평균: 1.05)는 intra-rater reliability (평균: 0.74)에 비해 약 1.4 배 큰 것으로 나타났다. 


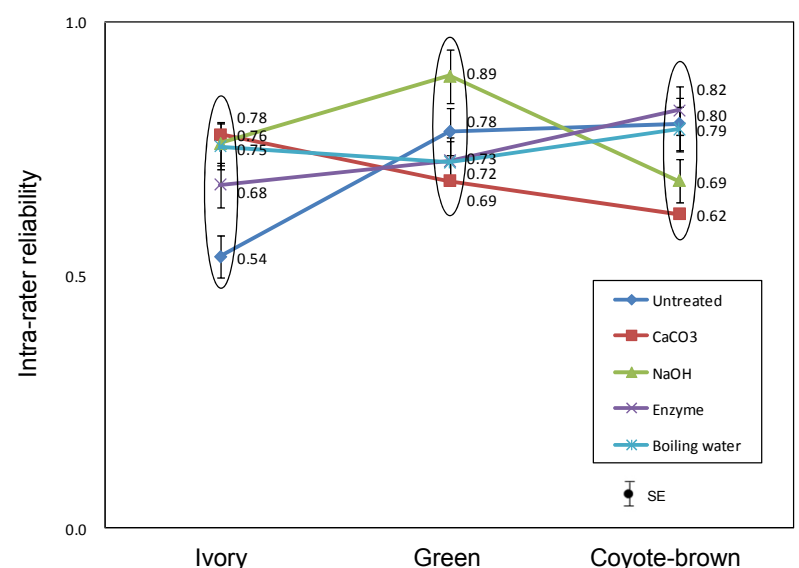

Figure 1. Interaction effect

(NaCOC color $\times$ scouring method) of intra-rater reliability

Table 3. Inter-rater reliability ANOVA

\begin{tabular}{l|rrrrc}
\hline \multicolumn{1}{c|}{ Source } & \multicolumn{1}{c}{$\boldsymbol{d} \boldsymbol{f}$} & SS & MS & $\boldsymbol{F}$ & $\boldsymbol{p}$ \\
\hline NaCOC color(C) & 2 & 0.08 & 0.04 & 2.33 & .106 \\
Scouring method(M) & 4 & 0.15 & 0.04 & 2.00 & .106 \\
Sensibility adjective(SA) & 8 & 0.41 & 0.05 & $2.63^{*}$ & .015 \\
$\mathrm{C} \times \mathrm{M}$ & 8 & 0.42 & 0.05 & $2.69^{*}$ & .013 \\
$\mathrm{C} \times \mathrm{SA}$ & 16 & 0.62 & 0.04 & $2.00^{*}$ & .026 \\
$\mathrm{M} \times \mathrm{SA}$ & 32 & 0.63 & 0.02 & 1.02 & .458 \\
Error & 64 & 1.23 & 0.02 & & \\
\hline Total & 134 & 3.55 & & & \\
\hline
\end{tabular}

(Note) ${ }^{*} p<.05 ;{ }^{* *} p<.01$.

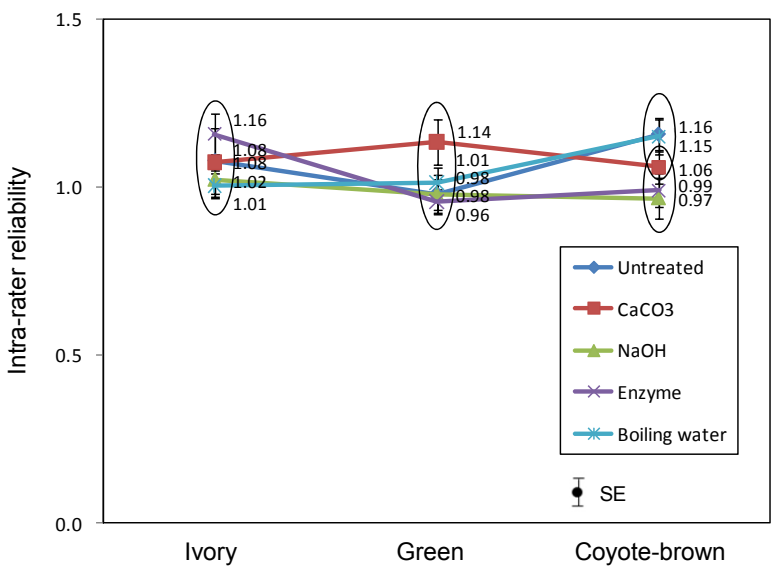

Figure 2. Interaction effect

(NaCOC color $\times$ scouring method) of inter-rater reliability

\subsection{Preferred scouring method for $\mathrm{NaCOC}$}

$\mathrm{NaCOC}$ 시감성을 9 가지 각 시감성 평가 형용사 쌍에 대 해 ANOVA를 수행한 결과, 섬유의 색상과 정련 방법의 교 호작용에서 모두 유의한 차이를 가지는 것으로 나타났다 (표 4 참조). 예를 들어 '값싸보이는-고급스러운' 감성에서 는 섬유의 색상과 정련 방법의 교호작용이 유의 $(p<.001)$ 한 것으로 나타났다(그림 3 참조).

Table 4. ANOVA results(NaCOC color, scouring method and interaction) by nine sensibility adjectives

\begin{tabular}{l|c|c|c}
\hline \multirow{2}{*}{$\begin{array}{l}\text { Visual sensibility } \\
\text { adjective }\end{array}$} & \multicolumn{3}{|c}{$p$-value } \\
\cline { 2 - 4 } & $\begin{array}{c}\text { NaCOC color } \\
\text { (C) }\end{array}$ & $\begin{array}{c}\text { Scouring method } \\
(\mathrm{M})\end{array}$ & $\mathrm{C} \times \mathrm{M}$ \\
\hline Bright - Dark & $<.001$ & $<.001$ & $<.001$ \\
Clear - Murky & $<.001$ & $<.001$ & $<.001$ \\
Heavy - Light & $<.001$ & $<.001$ & $<.001$ \\
Vivid - Subdued & $<.001$ & $<.001$ & $<.001$ \\
Warm - Cool & $<.001$ & $<.001$ & .002 \\
Fresh - Stale & $<.001$ & $<.001$ & $<.001$ \\
Strong - Weak & $<.001$ & $<.001$ & $<.001$ \\
Showy - Plain & .004 & .311 & $<.001$ \\
Luxurious - Cheap & $<.001$ & $<.001$ & $<.001$ \\
\hline
\end{tabular}

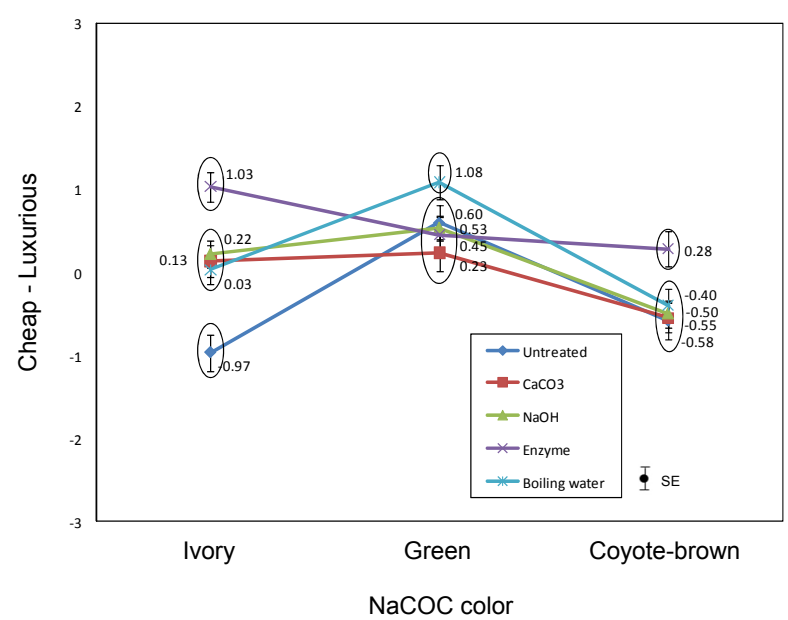

Figure 3. Interaction effect of $\mathrm{NaCOC}$ color and scouring method ('Luxurious - Cheap')

정련 방법이 섬유의 색상 별 시감성에 미치는 효과를 post-hoc analysis한 결과, 정련 방법에 따라 시감성이 유 의하게 변하는 것으로 나타났다(표 5 참조). 예를 들어 '차 가운-따뜻한' 감성에서 ivory 섬유를 끓는 물로 처리(1.3 
점)한 경우 화학적 방법 $\left(\mathrm{Na}_{2} \mathrm{CO}_{3}: 0.7\right.$ 점, $\mathrm{NaOH}: 0.9$ 점 $)$ 에 비해 유의하게 따뜻한 감성이 증대되는 것으로 나타났다. 또 한, '칙칙한-산뜻한' 감성에서도 coyote-brown 섬유를 끓 는 물로 처리 $(0.1$ 점)한 경우 다른 방법들 $(\mathrm{NaOH}:-1.3$ 점,
$\mathrm{Na}_{2} \mathrm{CO}_{3}$ : -0.9점, enzyme: -0.6점)에 비해 산뜻한 감성이 유의하게 증대되는 것으로 나타났다. 그러나 '탁한-맑은' 감 성에서 green 섬유는 4 가지 정련 방법에 따른 감성의 차이 가 유의하지 않은 것으로 나타났다.

Table 5. Overall visual sensibility evaluation results at each sensibility adjective by NaCOC color and scouring method

\begin{tabular}{|c|c|c|c|}
\hline $\begin{array}{l}\text { Visual sensibility } \\
\text { adjective pair }\end{array}$ & Ivory & Green & Coyotebrown \\
\hline Bright $(+)-$ Dark (-) & $\mathrm{C}(0.6) \mathrm{B}(0.7) \mathrm{D}(1.0), \mathrm{A}(1.1)$ & $\mathrm{A}(-1.4) \mathrm{C}(-1.1), \mathrm{D}(-0.8), \mathrm{B}(-0.5)$ & $\mathrm{B}(-2.0), \mathrm{A}(1.3) \mathrm{C}(-0.3), \mathrm{D}(0.4)$ \\
\hline Clear $(+)-$ Murky (-) & $\mathrm{C}(-0.3), \mathrm{B}(0.2) \mathrm{D}(0.6), \mathrm{A}(0.7)$ & $\mathrm{D}(-1.2) \mathrm{A}(-1.2), \mathrm{C}(-1.2) \mathrm{B}(-0.8)$ & $\mathrm{B}(-1.5), \mathrm{A}(1.1), \mathrm{C}(-0.6), \mathrm{D}(0.2)$ \\
\hline Heavy $(+)-$ Light $(-)$ & $\mathrm{A}(-0.8) \mathrm{D}(-0.6) \mathrm{B}(-0.3) \mathrm{C}(-0.1)$ & $\mathrm{D}(0.5, \mathrm{~B}(0.6) \mathrm{C}(1.1) \mathrm{A}(1.2)$ & $\mathrm{D}(0.2), \mathrm{C}(0.6), \mathrm{A}(1.3), \mathrm{B}(1.8)$ \\
\hline Vivid (+) - Subdued (-) & $\mathrm{D}(-0.8) \mathrm{A}(-0.6), \mathrm{B}(-0.5), \mathrm{C}(-0.2)$ & $\mathrm{D}(0.2, \mathrm{~B}(0.2) \mathrm{C}(0.6, \mathrm{~A}(0.8)$ & $\mathrm{D}(-0.3), \mathrm{C}(0.2), \mathrm{A}(0.6), \mathrm{B}(1.2)$ \\
\hline Warm $(+)-$ Cool (-) & $\mathrm{C}(0.3) \mathrm{A}(0.7), \mathrm{B}(0.9), \mathrm{D}(1.3)$ & $\mathrm{A}(-0.1) \mathrm{C}(0.1), \mathrm{D}(0.1 \mathrm{~B}(0.4)$ & $\mathrm{B}(0.8), \mathrm{C}(0.8), \mathrm{A}(1.0), \mathrm{D}(1.3)$ \\
\hline Fresh $(+)-$ Stale $(-)$ & $\mathrm{C}(-0.2), \mathrm{D}(0.1) \mathrm{B}(0.1), \mathrm{A}(0.2)$ & $\mathrm{D}(-1.3), \mathrm{A}(-0.9), \mathrm{C}(-0.8), \mathrm{B}(-0.7)$ & $\mathrm{B}(-1.3), \mathrm{A}(0.9), \mathrm{C}(-0.6), \mathrm{D}(0.1)$ \\
\hline Strong $(+)-$ Weak $(-)$ & $\mathrm{D}(-0.4) \mathrm{A}(-0.3), \mathrm{B}(0.2), \mathrm{C}(0.2)$ & $\mathrm{D}(0.3) \mathrm{B}(0.5), \mathrm{C}(0.9), \mathrm{A}(1.0)$ & $\mathrm{D}(0.0), \mathrm{C}(0.5), \mathrm{A}(1.0), \mathrm{B}(1.5)$ \\
\hline Showy $(+)$ - Plain (-) & $\mathrm{C}(-1.2), \mathrm{A}(-0.9), \mathrm{B}(0.8), \mathrm{D}(-0.7)$ & $\mathrm{D}(-1.5), \mathrm{B}(-1.0), \mathrm{C}(-0.8), \mathrm{A}(-0.6)$ & $\mathrm{C}(-0.6), \mathrm{A}(-0.5), \mathrm{D}(-0.4), \mathrm{B}(-0.1)$ \\
\hline Luxurious (+) - Cheap (-) & $\mathrm{C}(-1.0) \mathrm{B}(-0.2), \mathrm{A}(0.1), \mathrm{D}(0.0)$ & $\mathrm{D}(-1.1), \mathrm{B}(-0.5), \mathrm{C}(-0.5), \mathrm{A}(-0.2)$ & $\mathrm{C}(-0.3), \mathrm{D}(0.4) \mathrm{B}(0.5), \mathrm{A}(0.6)$ \\
\hline
\end{tabular}

(Note) A: $\mathrm{Na}_{2} \mathrm{CO}_{3}, \mathrm{~B}: \mathrm{NaOH}, \mathrm{C}$ : enzyme, D: boiling water; A horizontal line denotes no significant difference among the conditions at $\alpha=.05$

\section{Discussion}

본 연구는 친환경 섬유 소재인 $\mathrm{NaCOC}$ 에 대한 시감성 평 가를 통해 시감성 평가 방법의 신뢰성 (intra-, inter-rater reliability)을 분석하였다. 분석 결과, inter-rater reliability (평균 $\mathrm{SD}=1.06$ )는 intra-rater reliability (평균 $\mathrm{SD}=$ 0.74 )에 비해 약 1.4 배 더 큰 것으로 나타났으나 $\mathrm{NaCOC}$ 색상과 정련 방법에 의한 변화 경향성은 없는 것으로 분석되 었다. 한편 이와 유사한 연구로 Yick et al.(1995)이 수행한 남성 의류의 촉감에 대한 reliability는 6점 척도를 기준으로 0.93으로 도출(7점 척도를 기준으로는 1.08)되어 본 연구 의 reliability 분석 결과와 유사한 것으로 나타났다. 본 연 구에서 파악된 intra- \& inter-rater reliability는 추후 관 련 연구 분야에서 유용한 참조 자료로 활용될 수 있을 것으 로 예상된다.

$\mathrm{NaCOC}$ 에 대한 시감성은 섬유가 가지는 본래의 색상과 정련 방법에 따라 유의하게 달라지는 것으로 나타났다. 예
를 들어 '은은한(-) 선명한(+)' 감성에서 ivory 섬유를 $\mathrm{NaOH}$ 로 정련한 경우 시감성은 은은함 $(-0.5$ 점) 쪽에 가까 웠으나, green과 coyote-brown 섬유를 $\mathrm{NaOH}$ 로 정련한 경우는 오히려 선명함(+) (green: 0.2점; coyote-brown: 1.2 점) 쪽에 가까웠다. 이러한 평가 결과는 섬유가 가지는 본 래 색상이 시감성 평가에 중요한 영향을 미치는 것으로 해석 될 수 있다. 그리고 같은 색상의 섬유라도 정련 방법에 따라 서 상이한 시감성을 가지는 것으로 나타났다. 예를 들어, 고 급스러운 시감성 측면에서 ivory 섬유는 정련 처리되지 않 았을 때 값싸보이는 시감성(-0.97점)이었으나 enzyme으 로 정련 처리된 경우 고급스러운 시감성(1.03점)으로 변화 되는 것으로 나타났다.

$\mathrm{NaCOC}$ 의 정련 방법들 중 자연적 정련 방법(예: 끓는 물) 이 화학적 정련 방법 $\left(\mathrm{Na}_{2} \mathrm{CO}_{3}, \mathrm{NaOH}\right)$ 에 비해 우수할 수 있음이 파악되었다. 기존 $\mathrm{NaCOC}$ 정련 과정에서는 정련 처 리 효과가 좋은 화학적 방법들이 주로 이용되고 있었다. 그 러나 친환경 소재에 대한 소비자들의 관심이 증대되면서 섬 유의 자연적 정련 방법에 관한 연구가 점차 활성화되고 있 
다(Tzanov et al., 2001; Wang et al., 2007). 본 연구의 결 과에서는 특정 시감성 측면(예: 고급스러운)에서 자연적 정 련 방법(예: 끓는 물)이 화학적 방법에 비해 긍정적인 효과 를 줄 수 있는 것으로 나타났으나 모든 시감성 측면에서 우 수하지는 않았다. 그러므로 $\mathrm{NaCOC}$ 의 적정 정련 방법은 직 물의 사용 용도 및 색상, 그리고 환경 등에 대한 복합적인 고려를 바탕으로 선택될 필요가 있다.

본 연구의 시감성 평가는 20 30대의 여성 실험 참여자들 로만 수행되었으나 추후 연구에는 중 - 장년층과 같은 다양 한 연령대를 대상으로 확대될 필요가 있다. $\mathrm{NaCOC}$ 로 제직 된 직물은 유아복에서 기성복에 이르기까지 다양한 연령층 의 의복에 적용될 것으로 예상된다. 그러므로 사용자의 연령 대 별 시감성을 고려한 감성적 직물 설계가 필요하다. 특히 실질적인 의복 구매 능력이 있을 것으로 예상되는 중년층과 시력에 노화가 발생되는 장년층을 대상으로 각각의 시감성 변화 경향을 분석하는 후속 연구가 필요할 것으로 판단된다.

\section{Acknowledgements}

This research was jointly supported by the Basic Science Research Program through the National Research Foundation of Korea(NRF) funded by the Ministry of Education, Science, and Technology(2010-0028229) and Korea Ministry of Environment (MOE) as "Project of a School of Ecodesign."

\section{References}

Dickerson, D., Lane, E. and Rodriguez, D., Naturally Colored Cotton: Resistance to Changes in Color and Durability When Refurbished with Selected Laundry Aids, California Agric. Tech. Inst., California State University, Fresno, California, 1999.

Hua, S., Wang, X., Yuan, S., Shao, M., Zhao, X., Zhu, S. and Jiang, L., Characterization of pigmentation and cellulose synthesis in colored cotton fibers. Crop Science Society of America, 47, 1540-1546, 2007.

Kang, S. and Epps, H., Effect of scouring on the color of naturally-colored cotton and the mechanism of color change. American Association of Textile Chemists and Colorists Review, 8(7), 38-43, 2008

Lewin, M. and Pearce, E. M., Handbook of Fiber Science and Technology. CRC Press: New York, USA, 1985.

Lee, K. and Nam, S., A study on structure of sensibility on colors. Journal of Korean Society of Color Studies, 13, 105-116, 1999.

Ou, L., Luo, M., Woodcock, A. and Wright, A., A study of colour emotion and colour preference, part I: colour emotions for single colours.
Color Research \& Application, 29(4), 292-298, 2004.

Seo, M., A study on the functional improvement of natural dyed fabrics. The Korean Journal of Community Living Science, 19, 213-221, 2008.

Tzanov, T., Margarita, C., Georg, G. and Artur, C., Bio-preparation of cotton fabrics. Enzyme and Microbial Technology, 29, 357-362, 2001.

Wang, Q., Fan, X., Hua, Z., Gao, W. and Chen, J., Influence of combined enzymatic treatment on one-bath scouring of cotton knitted fabrics. Biocatalysis and Biotransformation. 25(1), 9-15, 2007.

Woo, S. and Cho, G., A study on compound sensibility of odors and colors for aromatic fabric design. Korean Journal of the Science of Emotion \& Sensibility, 6, 37-47, 2003.

Yick, K. L., Cheng, K. P. and How, Y. L., Subjective and objective evaluation of men's shirting fabrics. International Journal of Clothing Science and Technology, 7(4), 17-29, 1995.

\section{Author listings}

Jangwoon Park: parkjw@postech.ac.kr

Highest degree: BS, Industrial Engineering, Ajou University Position title: Ph. D. student, Department of Industrial \& Management Engineering, POSTECH

Areas of interest: Digital human modeling \& simulation, User-centered product design \& development, Anthropometric and biomechanical methods for product \& clothing design, User interface, Usability testing

Chang Yoon: thursday@postech.ac.kr

Highest degree: MS, Department of Industrial \& Management Engineering, POSTECH

Position title: Research engineer, Emotional Design Group, LG Electronics

Areas of interest: Ergonomic product design \& development, Sensibility evaluation, User interface design, Affective textile design, Graphic design

Wongi Hong: wonkiman@postech.ac.kr

Highest degree: BS, Electrical Engineering, University of Ulsan Position title: M.S. student, Department of Industrial \& Management Engineering, POSTECH

Areas of interest: Human computer interaction, Ergonomic product design \& development, User interface design, Biosignal analysis, Sensibility evaluation

Myungeun Lee: myung@yonsei.ac.kr

Highest degree: M.S. Clothing \& Textiles, Yonsei University Position title: Ph.D. student, Department of Clothing \& Textiles, Yonsei University

Areas of interest: Digital clothing \& e-textiles, Fabric sound, Natural dyeing of fabrics, Naturally colored organic cotton 
Ahreum Han: asheley84@paran.com

Highest degree: MS, Clothing \& Textiles, Yonsei University Areas of interest: Digital clothing \& e-textiles, Fabric sound, Natural dyeing of fabrics, Naturally colored organic cotton

Youngjoo Chae: fchae@paran.com

Highest degree: BS, Clothing \& Textiles, Yonsei University

Position title: M.S. student, Department of Clothing \& Textiles, Yonsei University

Areas of interest: Digital clothing \& e-textiles, Fabric sound, Natural dyeing of fabrics, Naturally colored organic cotton

Gilsoo Cho: gscho@yonsei.ac.kr

Highest degree: Ph.D. Clothing and Textiles, Virginia Tech.

Position title: Professor, Department of Clothing \& Textiles, Yonsei

University

Areas of interest: Digital clothing \& e-textiles, Fabric sound, Touch and luster, Phase change materials, Textiles and clothing evaluation in neo-science, Natural dyeing of fabrics, Development of antimicrobial finished product, Development of thermostatic fabrics, Naturally colored organic cotton
Heecheon You: hcyou@postech.ac.kr

Highest degree: $\mathrm{PhD}$, Industrial Engineering, Pennsylvania State University

Position title: Associate Professor, Department of Industrial \& Management Engineering, POSTECH

Areas of interest: Ergonomic product design \& development, User interface design \& evaluation, Digital human modeling \& simulation, Human performance \& workload assessment, Work-related musculoskeletal disorders (WMSDs) prevention, Usability testing

Date Received : 2010-11-01

Date Revised :2011-02-11

Date Accepted : 2011-02-21 